\title{
Nepomuceno e a gênese da canção de câmara brasileira (1a. parte)
}

Rodolfo Coelho de Souza' (Universidade de São Paulo)

\section{Resumo}

Este artigo busca avaliar a produção vocal camerística de Nepomuceno, revendo sua posição na história da música brasileira, refutando a hipótese de seu papel como fundador e redimensionando seu projeto como sendo o de escrever canções, em português ou em línguas estrangeiras, nos moldes do Lied alemão e da Mélodie francesa, como gêneros exemplares do romantismo cosmopolita. Demonstra-se a seguir que Nepomuceno adere ao modelo de imitação dos grandes mestres, recomendado pela Academia de Belas Artes de seu tempo, tomando a obra de Brahms como modelo. Essa influência é vista no uso de alternância de texturas como artifício para definição da forma e no emprego distintivo de dois modos estilísticos, Volkslied e Kunstlied, que Nepomuceno empresta de Brahms para contrastar canções emparelhadas duas a duas em seus opus. Estuda-se também como a questão do uso do folclore foi inflada pela musicologia modernista quando, na verdade, Nepomuceno a utiliza como tópicos estilísticos carregados de significados semânticos para a realização do ideal do Lied como de uma perfeita simbiose entre poesia e música.

Palavras-chave: Alberto Nepomuceno; música brasileira; canção brasileira.

\footnotetext{
1 Professor Livre Docente no Departamento de Música da Escola de Comunicações e Artes da Universidade de São Paulo em Ribeirão Preto. Atua na área de Composição Musical e Musicologia Analítica, pesquisando principalmente sobre os seguintes temas: composição musical auxiliada por computadores, teoria da música atonal, musicologia analítica da música brasileira dos séculos XIX a XXI. Desde 1984 até hoje tem sido membro da direção artística do Festival Música Nova de Santos e São Paulo. Foi coordenador do Laboratório de Computação Musical da Universidade Federal do Paraná (2000-2005) e é colaborador da OSESP.
} 


\section{À guisa de introdução: fundadores e precursores}

A historiografia da música brasileira foi regida, desde seu início em princípios do século vinte, por uma ideologia de fundo republicano positivista que almejava a formação de uma identidade nacional através da projeção de certas personalidades, alçadas ao papel de fundadores míticos. Esse projeto prolongou-se durante o Modernismo, com algumas nuances distintivas, sobretudo na ênfase aos aspectos folclóricos, mas continuou dominante durante todo o século vinte.

O legado de Nepomuceno prestou-se perfeitamente a integrar esse projeto. A liderança que exerceu no pensamento musical de sua geração facilitou aos historiadores enquadrar sua atuação no papel de precursor do modernismo, especialmente quanto ao uso de traços característicos do folclore em sua música (sobretudo empréstimos de melodias, ritmos africanos e configurações modais), e, por outro, de fundador de um gênero caro ao modernismo, a canção de câmera em português.

Não vou repetir aqui o que escrevi em outro ensaio² a respeito da

34 parcialidade da visão da obra de Nepomuceno como sendo apenas precursora do modernismo folclorista, o que faz projetar uma sombra de esquecimento sobre sua valiosa contribuição à introdução de técnicas progressistas na linguagem musical brasileira de seu tempo. Entretanto, ao abordar aqui o conjunto de sua produção vocal camerística, é necessário, ainda outra vez, retificar a voz corrente de nossa historiografia, colocando na devida proporção o frequentemente alegado papel de Nepomuceno como fundador da canção de câmera brasileira.

Em Mariz (2002) encontramos uma habilidosa declinação dessa receita. Seriam precursores o Pe. José Maurício, Domingos Caldas Barbosa e Carlos Gomes, porque escreveram modinhas. Para aquela geração de musicólogos não interessava conferir ao gênero das modinhas um estatuto de canções de câmera. Isso estragaria seu plano para a construção dos grandes vultos da música brasileira: José Maurício, o grande compositor de música sacra, Caldas Barbosa, o

\footnotetext{
${ }^{2}$ Ver Coelho de Souza, 2006.
} 
grande modinheiro, Carlos Gomes, o grande operista e finalmente Nepomuceno, o fundador da canção de câmera brasileira, porque, segundo se afirma, teria consolidado o canto em português. Voltaremos a este ponto oportunamente na segunda parte deste ensaio.

Como se constata, a corrente que tem sido dominante na musicologia brasileira pareceu mais interessada na construção de vultos históricos idealizados do que numa história baseada em fatos documentados. Onde havia lacunas, a imaginação ganhou asas. Seja por exageros, seja por descréditos, a compreensão da obra de Nepomuceno foi distorcida por essa ideologia. Talvez o próprio compositor tenha colaborado para avalizar essa postura quando participou do movimento de recuperação da obra do Pe. José Maurício Nunes Garcia, almejando forjar um vulto histórico de modo semelhante ao que Mendelssohn havia feito com J. S. Bach.

Provavelmente Anna Maria Kieffer foi a primeira pesquisadora que questionou a suposição de que a obra vocal de Nepomuceno teria sido fundadora da canção de câmara brasileira, não obstante seu declarado apreço por sua obra. Como as pesquisas de Kieffer visavam produções artísticas e não receberam formalização acadêmica, acabaram infelizmente tendo pouco impacto na nossa musicologia. Afirma ela ter localizado na Biblioteca Nacional

uma grande quantidade de músicas impressas a partir de 1830, quando essa atividade começou no Brasil. [...] Os compositores do período [...] tiveram como parceiros os maiores poetas brasileiros da época, como Gonçalves Dias, Álvares de Azevedo, Castro Alves, Fagundes Varela, Casimiro de Abreu e muitos outros (Kieffer, 2007).

Na busca desse repertório esquecido dos anos 1830-70, Kieffer localizou diversas canções de Rafael Coelho Machado, um dos mais influentes músicos brasileiros daquele período, sobre poemas de Gonçalves Magalhães, um dos iniciadores do movimento romântico brasileiro na literatura. Muitas dessas canções foram publicadas no álbum Urânia, baseado no livro homônimo publicado pelo poeta em 1862. Mesmo sem termos ainda condições de descortinar a qualidade dessa música, sua mera existência prova que a canção 
de câmera brasileira floresceu ao longo do século dezenove, antes da contribuição de Nepomuceno.

O significado da contribuição das canções de Nepomuceno para nossa história deve ser buscada em outra linha de argumentação. Tudo que hoje se conhece de música vocal brasileira anterior a Nepomuceno filia-se diretamente à influência da ópera italiana, inclusive a modinha. Nepomuceno percorre um caminho diverso ao assimilar a influência direta do Lied alemão e da Mélodie francesa. Não é por acaso que entre as primeiras canções de Nepomuceno encontramos algumas sobre poemas em italiano, e a seguir diversas em alemão e francês, entremeadas com algumas em português. Ao voltar para o Brasil, depois dos estudos na Europa, predominarão na sua produção as canções em português, mas Nepomuceno jamais abandonará o hábito de compor sobre textos em italiano, alemão ou francês.

A assimilação do modelo do Lied tem diversas implicações. A primeira está na relação texto-música. Nas modinhas, e mesmo no cancioneiro mais elaborado de Gomes e Coelho Machado, o poema é considerado letra de música, isto é, não precisa necessariamente ter vida autônoma, basta servir ao propósito 36 de suporte do canto. Já o paradigma do Lied tem como ideal uma perfeita simbiose entre poema e música, sendo ambos de alta qualidade artística. Um compositor de Lied quase sempre utiliza poemas previamente publicados, de autores aclamados ou de talentos emergentes. Seu esforço é criar música que amplifique e revele o sentido latente do poema, implicando ainda na hipótese de que o todo resultará maior do que a soma das partes. Trata-se portanto de um projeto baseado em ideais típicos do romantismo alemão em que se almeja exprimir a sutileza das emoções humanas profundas, em oposição à expressão direta das emoções, buscada pela ópera italiana.

O projeto das canções de Nepomuceno enquadra-se no paradigma do Lied e provavelmente encontrar-se-ia poucos precedentes disso na história da música brasileira. Essa poderia ser considerada sua verdadeira contribuição ao gênero. Rotineiramente ele utilizou poetas diferentes, buscando nutrir sua inspiração com o desafio de identificações renovadas. A forma de suas canções exibe uma grande variedade de soluções, com poucas repetições de receitas 
prontas, pois cada novo poema deve demandar uma solução formal adequada à sua expressão. Nesse sentido não importava para ele se a canção era em português ou língua estrangeira, contanto que o resultado alcançasse os desejados efeitos poéticos de ambivalência na conexão entre poesia e música.

Nossa musicologia tem visto a questão por outra ótica. Vasco Mariz é paradigmático quando louva o cancioneiro de Nepomuceno com a seguinte linha de argumentação:

Nepomuceno sempre teve a preocupação das coisas brasileiras. Entoava canções do Nordeste e colecionava versos populares - estava destinado a convencer o público brasileiro da qualidade de nossa língua e do folclore. Não desconhecia a dificuldade da aceitação do Lied em português, da canção brasileira. Sem forças para lutar, foi cauteloso a princípio e, influenciado por Schumann e Grieg, compôs parte de sua obra vocal um pouco à maneira daqueles músicos, sobre textos estrangeiros e sem qualquer acento nacionalista. Ao ascender à direção do Instituto Nacional de Música, sentiu-se forte para tentar uma campanha vigorosa pelo canto em português e, a partir de 1902, compôs quase que exclusivamente utilizando a língua nacional (Mariz, 2002, p. 58).

Vamos nos deter, ao longo desse artigo, em diversos pontos da postulação de Mariz. A primeira afirmação que contestaremos é a ideia de que na fase inicial faltaram-Ihe forças para lutar e por isso ele submeteu-se à influência de Schumann e Grieg. Procurei demonstrar em outros artigos e farei o mesmo aqui, que o projeto estético de Nepomuceno não era modernista, partindo de postulações que negassem o passado. Ao contrário, seu projeto era semelhante ao das Academias de Belas Artes, que visava consolidar a práxis do artista a partir do estudo e da imitação das obras dos grandes mestres. Sobre essa fundação, Nepomuceno tem a particularidade de estar sempre muito atento aos movimentos progressistas de seu tempo e é nesse sentido que ele traz contribuições originais à música brasileira. A questão da utilização de fontes folclóricas é uma delas, mas de modo algum a única. Quanto às influências que sofreu na composição das canções, defendemos que a primeira impressão duradoura em sua produção, aliás quase óbvia, é a de Brahms. Em seguida há influências decisivas do ambiente francês, em que predominavam, de um lado o wagnerianismo, como em Franck e Chausson, e de 
outro, o uso de modalismos, como em Fauré e Debussy. Se traços da influência direta de Brahms são fáceis de localizar, a dos franceses é mais difusa, tornando mais difícil estabelecer relações diretas com a obra dos autores mencionados. O motivo para isso parece simples: a canção de Brahms descendia de uma tradição mais antiga e sedimentada, de modo que seria quase impossível para Nepomuceno deixar de transparecer sua dívida. Já, quanto aos franceses, a atuação de Nepomuceno foi muitas vezes simultânea, e suas produções às vezes resultaram tão originais quanto a deles, ainda que não se possa deixar de reconhecer a dívida do compositor brasileiro ao ambiente francês que propiciou essas criações. Um bom exemplo disso é que Chausson e Nepomuceno ambos compuseram canções sobre o poema Oraison de Maeterlinck. O manuscrito da canção de Nepomuceno registra a data de 1894 e utiliza técnicas de ultracromatismo baseadas em relações de mediantes. A canção de Chausson é de 1895, portanto posterior à de Nepomuceno, e embora também ultra-cromática, utiliza um processo de deslizamento contínuo wagneriano que sem certos aspectos soa mais previsível do que aquele conseguido por Nepomuceno.

\section{As canções de Brahms como modelo para Nepomuceno}

A influência de Brahms nas primeiras obras de Nepomuceno escritas durante seus estudos na Europa fica ainda mais saliente no período em que trabalhou com Herzogenberg, tomando contato direto com a escola que orbitava em torno de Brahms, estrela de maior grandeza da música de câmera alemã no período. A influência de Brahms na música instrumental de Nepomuceno é imediatamente reconhecível em obras como a Sonata em Fá para piano, nos três quartetos de corda (aliás o primeiro ainda é do ano anterior de residência na Itália) e na Sinfonia em Sol menor. Entretanto é possível reconhecer a dívida para com Brahms mesmo em obras daquele período cuja influência de 
outros autores é mais evidente, como é o caso da Suite Antiga na versão para cordas, em relação a Grieg. ${ }^{3}$

Também na canção de câmera é possível estabelecer diversos paralelos com a concepção de Brahms em relação ao gênero do Lied. Inevitavelmente será impossível distinguir com absoluta convicção se as influências são apenas de Brahms ou também de Schumann e Schubert, visto que o Lied alemão tem um elevado grau de continuidade estilística ao longo do século dezenove. Todavia é possível excluir qualquer influência de Hugo Wolff, bastando para tanto comparar as datas das obras que poderiam suscitar alguma suspeita de similaridade: quando as canções de Wolff se tornam públicas, as de Nepomuceno que parecem similares, já estavam compostas. É especialmente relevante registrar que as invenções de Nepomuceno quanto a cromatismos e relações enarmônicas foram concebidas independentemente e ao redor da mesma época, não se tratando portanto de um fenômeno de influência ou inter-textualidade, mas de Zeitgeist. Tal como Wolff, Nepomuceno é capaz de evitar os caminhos mais óbvios das resoluções harmônicas, ${ }^{4}$ enriquecendo as relações de sentido entre texto e melodia.

Que características dos Lieder de Brahms encontram eco nas canções de Nepomuceno? Um primeiro detalhe é que Nepomuceno aprende com Brahms a reagir ao sentido do poema modificando as texturas do acompanhamento. Hancock (1996, p.122) aponta que "a alteração do padrão do acompanhamento é uma das maneiras com que Brahms articula a forma em suas canções," particularmente nas canções com forma singular, ${ }^{5}$ escritas sobre poemas sem estrutura estrófica. Nepomuceno também utiliza esse artifício para estruturar a forma da canção e evitar a monotonia, mesmo quando utiliza poemas estróficos.

\footnotetext{
3 Em Coelho de Souza, 2008, demonstrei que a orquestração da Suite Antiga de Nepomuceno segue modelos de Brahms, ainda que a versão para piano seja claramente devedora da Suite Holberg de Grieg.

${ }^{4}$ Numa entrevista de 1996 com o compositor alemão Bertold Türcke, que naquela época vivia no Brasil, mostrei-Ihe canções de Nepomuceno em língua alemã. Ele imediatamente associou a linguagem musical dessas peças às de Wolff. Türcke observou que, em diversos momentos, o engenhoso emprego de cromatismos reforçava possíveis semelhanças estilísticas que todavia não seriam possíveis atribuir a uma influência mútua.

${ }^{5} \mathrm{O}$ termo forma singular é usado aqui como uma possível tradução para os conceitos de Durchkomponiert (em alemão) ou Through-composed (em inglês).
} 
O Exemplo 1 traz trechos da canção Mater Dolorosa que ilustram esse procedimento. Escrita no período da breve residência parisiense em 1894 - ainda no ano da conclusão dos estudos em Berlim - esta peça é todavia menos experimental do que outras do período que absorvem influências progressistas da mélodie franco-wagneriana, como se verá na segunda parte do estudo. Mater Dolorosa reflete a influência direta dos modelos brahmsianos aprendidos na residência alemã.

Exemplo 1 Quatro trechos de Mater Dolorosa Op.14 n.1 de Nepomuceno
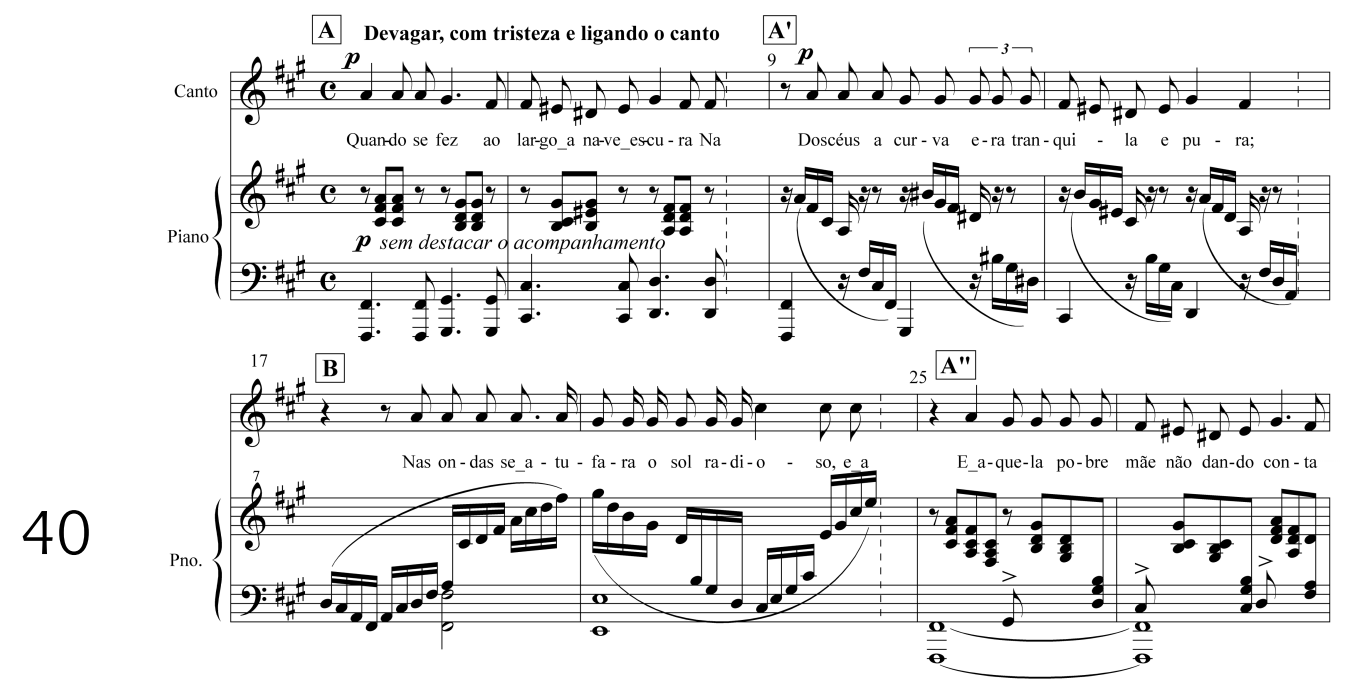

O poema de Gonçalves Crespo utilizado nesta canção é um perfeito exemplo de soneto decassílabo parnasiano, que emprega acentos heroicos (nas sílabas 6 e 10) e sáficos (nas sílabas 4, 8 e 10), com rimas alternadas abba/abba/ccd/eed. A forma da música ressoa as estrofes do poema, resultando em AA'BA", para a clareza da qual contribui a progressão das texturas demonstrada no Exemplo 1.

Em outra canção daquele ano, Le Miroir d'Or, sobre versos de Henri Piazza, aliás também um soneto, a forma musical é de novo um AABA, porém somente devido à estrutura melódico-harmônica, sendo que a textura permanece bem mais uniforme ao longo da canção, como outrossim é frequente encontrar nas canções dos compositores franceses, como Fauré e Chausson. 
Em algumas outras canções, Nepomuceno empregará esta mesma solução de associar a forma do soneto à forma musical AABA. Porém o tratamento do material apresentará muitas variantes porque Nepomuceno não só respeita as características estilísticas do modelo que emprega, seja do Lied alemão, seja da Mélodie francesa, como também foi seu propósito encontrar soluções inovadoras para o problema de compor música sobre sonetos, levando em conta o prestígio que essa forma poética tinha na literatura brasileira do seu tempo.

Um segundo ponto que poderia revelar uma influência de Brahms é quanto à escolha de poetas. O compositor alemão escreveu cerca de 200 canções, das quais diversas empregam textos de poetas de primeira grandeza, como Goethe, Eichendorff, Heine, Möricke e Brentano, mas muitas outras empregam, deliberadamente, textos de poetas menores como Groth, Lemcke e principalmente Daumer. Mas nem por isso a música de Brahms dessas canções é de qualidade inferior. A literatura, ainda durante a vida do compositor, registrou críticas a Brahms por essas escolhas, lamentando que se ele tivesse escolhido poetas mais significativos, o resultado final seria ainda melhor. Brahms contestava isso dizendo que considerava importante escolher poemas para os quais a música tivesse alguma coisa a contribuir, pois muitos grandes poemas the pareciam autossuficientes, tornando a música supérflua ou um estorvo ao poema (Braus, 1988, p. 128 apud Hancock 1996, p. 120).

Não conheço nenhuma declaração de Nepomuceno justificando a escolha dos cerca de 70 poemas que musicou. Mas constata-se uma postura semelhante à de Brahms na seleção frequente de poetas de segunda grandeza. Deixaremos de lado, nesse ponto, as canções em língua estrangeira, uma vez que Brahms só musicou textos em alemão e portanto não serve como paradigma de comparação. Entretanto, no que tange aos poetas de língua portuguesa, é notável que Nepomuceno tenha ignorado os grandes poetas brasileiros românticos e simbolistas, pois não escreveu nenhuma canção sobre poemas de Gonçalves de Magalhães, Casimiro de Abreu, Álvares de Azevedo, Junqueira Freire, Fagundes Varela, Sousândrade, Alphonsus de Guimaraens e Cruz e Sousa. A exceção fica por conta de uma única canção sobre poema de Gonçalves Dias. 
Por outro lado encontramos em sua produção uma extensa lista de nomes pouco conhecidos. Quase todos são poetas seus contemporâneos, dos movimentos parnasianos e simbolistas, alguns poetas regionais, outros apenas bissextos. Tudo levar a crer que Nepomuceno escolhia os poemas para suas músicas, assim como Brahms, pelo potencial de empatia que os textos Ihe despertavam, vislumbrando a possibilidade de acrescentar uma dimensão que julgava faltar à obra enquanto literatura. A grande maioria dos textos que musicou era de poetas que deve ter conhecido pessoalmente. Alguns se tornaram de fato bastante famosos, como Machado de Assis (1 canção), Olavo Bilac (3), Raimundo Correa (1) e Coelho Neto (2), mas nada indica que Nepomuceno tenha levado em conta o prestígio ou potencial de prestígio desse autores quando escolheu seus poemas. Em compensação é longa a lista de poetas cujos nomes soa apenas vagamente familiar, enquanto outros nem isso.

Finalmente, uma característica importante da obra vocal de Brahms é a distinção que ele faz entre dois subgêneros, Volkslied e Kunstlied. O primeiro está ligado à tradição do Lied folclórico (que em Brahms se confunde com a canção popular urbana) e o segundo é a canção como obra de arte no universo erudito.

42 Quanto ao primeiro grupo encontramos no catálogo de Brahms a menção a muitos arranjos de melodias folclóricas e, especialmente, diversas composições originais que procuram imitar o estilo daquelas canções populares ou folclóricas. No segundo grupo encontramos muitos Lieder conhecidos de Brahms, em que ele aplica, com desenvoltura, seu estilo pessoal, sem transparecer uma influência do Lied folclórico.

É certo que Nepomuceno estava ciente dessa diferença. É certo também que ele nutria um similar interesse pelo folclore brasileiro. Há notícias de que Nepomuceno coletou mais de uma centena de canções folclóricas ao longo de sua vida, mas, ao contrário de Brahms, não se interessou em fazer arranjos delas. Entretanto é possível reconhecer que algumas poucas canções de Nepomuceno, em número muito menor do que se propala, revelam algum tipo de influência folclórica, tais como Xácara, as Trovas op. 29 n. 2 e $A$ Jangada (aliás a única em que o traço folclórico, propriamente dito, é realmente inquestionável). Outras parecem bem distantes do universo popular, tais como as canções em língua 
estrangeira (com exceção do eco da música de salão em Mir träumte / Sonhel) e muitas em português, na verdade a maioria delas, ainda que diversas conservem características expressivas na melodia e na harmonia que possam nos fazer lembrar, ainda que vagamente, do estilo das canções populares brasileiras. Portanto podemos admitir que o modelo da separação entre Volkslied e Kunstlied na obra de Brahms, também encontra um paralelo, ainda que com outras peculiaridades, na obra de Nepomuceno.

\section{Heine, rito de passagem}

Creio que a esta altura já ficou clara a tese defendida neste artigo: o projeto do cancioneiro de Nepomuceno teria sido baseado na transposição para o Brasil de modelos europeus do Lied alemão e a também da Mélodie francesa, mesmo quando buscou inspiração em fontes populares brasileiras, uma vez que esse paradigma teria sido absorvido através do modelo das canções de Brahms. É necessário agora acrescentar mais evidências em suporte dessa hipótese.

Uma pesquisa de Susan Youens, recentemente publicada, chamou minha atenção para uma coincidência peculiar. Diz Youens (2007, p. xv) que "após 1850, os compositores frequentemente escolheram Heine para sua entrada em cena com o opus 1, como se colocar um poema de Heine em música fosse um rito de passagem, uma garantia de que se prestaria atenção ao seu trabalho." Ora, com Nepomuceno também acontece isso, ou quase isso. De fato não é em seu opus 1 que ele usará um texto de Heine, mas encontramos duas canções sobre poemas de Heine logo entre as cinco primeiras do seu cancioneiro completo publicado por Pignatari (2004).

A primeira dessas canções sobre um poema de Heine surge em tradução para o italiano com o nome de Serenata di um moro. Parece paradoxal que Nepomuceno tivesse usado Heine em italiano, mas Youens (2007, p. xxv) adverte que traduzir e musicar Heine em diferentes línguas foi uma prática comum naquela época. Por exemplo, sobre poemas de Heine em italiano, Youens menciona a existência de canções de Benedetto Junk, Niccolò van Waeterhout e 
Giovanni Sgambati. Lembremos que Nepomuceno estudou piano com Sgambati no Conservatório Santa Cecília de Roma durante o ano em que escreveu essa canção, o que sugere uma possível influência.

A segunda dessas canções, Der wunde Ritter, foi escrita em Berlim em 1893, portanto logo após a chegada do compositor àquela cidade. Recuperamos essa canção do manuscrito para sua primeira publicação na já mencionada edição de 2004 do cancioneiro completo. Num primeiro momento é difícil entender seu significado. A linha vocal pede um soprano ágil, capaz de executar passagens melismáticas, e uma extensão incomum para Nepomuceno, de Ré grave (às vezes insistentes) a Lá agudo. A despeito da linha vocal quase operística, a principal referência deste Lied é a tópicos do folclore alemão. O estilo é declamatório, de balada romântica, beirando o recitativo. A mistura de traços estilísticos italianos e alemães faz lembrar Carl Maria von Weber. O poema tem quatro estrofes e a música os interpreta com uma forma $\mathrm{ABCA}$. Na terceira estrofe, o cavaleiro ferido pela traição da amada conclama os rivais para a peleja. Nepomuceno utiliza o recurso de word painting para ilustrar a passagem, imitando o toque de trombetas que conclamam os cavaleiros para a disputa.

Exemplo 2 Trecho de Der wunde Ritter de Nepomuceno sobre poema de Heine
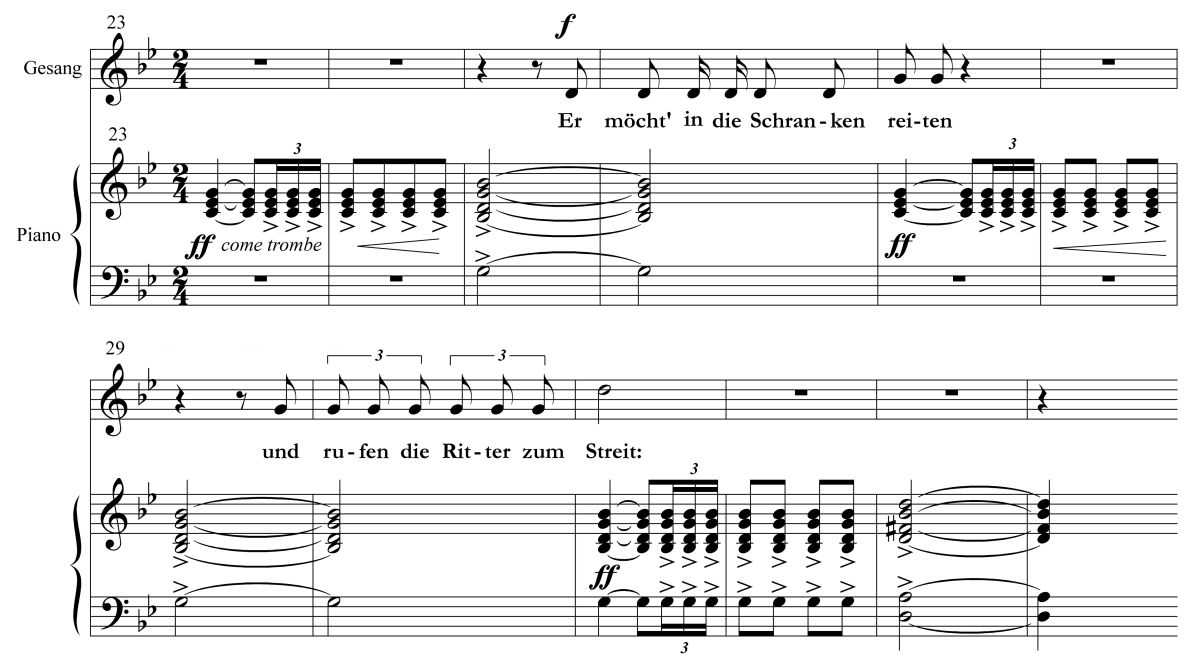

Esse passagem nos faz lembrar da abertura do Oberon de Weber, na qual aparece um motivo muito semelhante àquele do piano, orquestrado com 
trompetes e trompas, como aliás sugere a marcação de Nepomuceno na partitura de sua canção, em que pese a diferença de dinâmicas.

Exemplo 3 Fragmento da Abertura de Oberon de Carl Maria von Weber

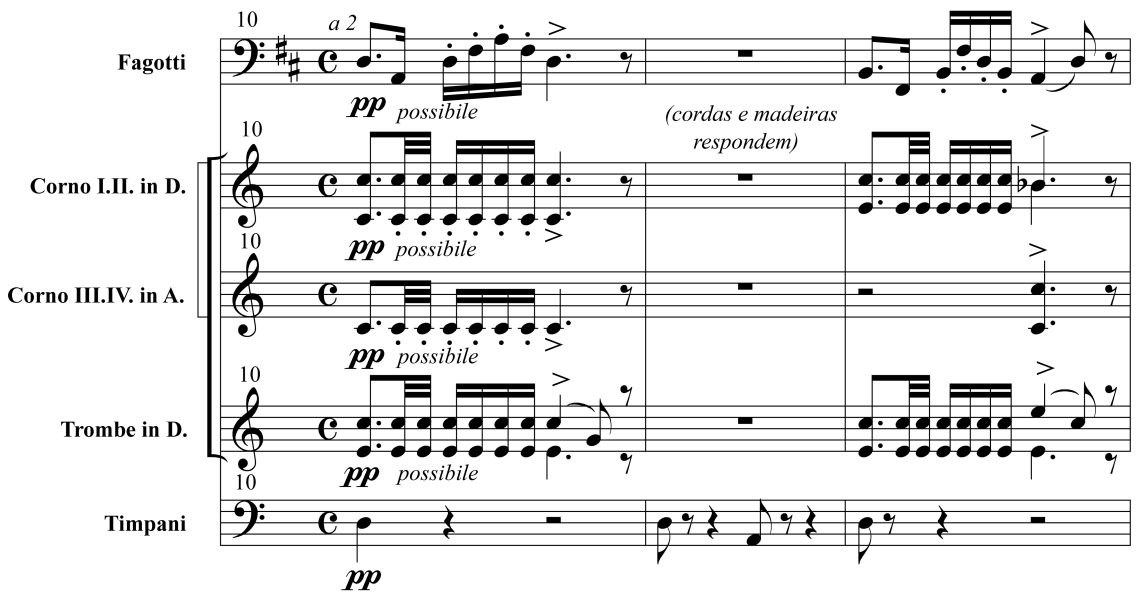

O propósito dessa comparação não é sugerir que Nepomuceno tenha necessariamente feito uma citação de Weber na sua canção, ainda que isso possa de fato ter acontecido. Nossa abordagem é a da teoria contemporânea da significação musical que procura tratar o problema das referências através da noção de tópico. Esse conceito foi inicialmente proposto para a música do período clássico, definindo-se tópicos como sendo uma espécie de dicionário de figuras musicais:

[...] a música do início do século dezoito desenvolveu um glossário de figuras características, que constituíram um rico legado para os compositores clássicos. Algumas dessas figuras eram associadas a vários sentimentos e afetos; outras tinham um sabor pictórico. Elas são chamadas aqui de tópicos - assuntos para o discurso musical. Tópicos aparecem como peças inteiras, ou seja, tipos, ou como figuras e progressões dentro de uma peça, isto é, estilos. A distinção entre tipos e estilos é flexível; minuetos e marchas representam tipos completos de composição, mas eles também fornecem estilos para outras peças (Ratner, 1980, p. 9).

Estudos recentes, como o de Agawu (2009, p. 45), defendem a persistência da significação dos tópicos de Ratner durante o romantismo, mencionando a permanência de "tipos" como minueto, giga, siciliana e marcha, e 
"estilos musicais" como militar, caça, pastoral e fantasia. Entretanto Agawu aponta também para a emergência de novos estilos e a consignação de novos significados a tópicos antigos. De acordo com Dickensheets (apud Agawu, 2009), o "estilo cavalheiresco", também chamado de "tópico do nobre cavaleiro" (que é a mitificação romântica deste personagem da literatura medieval), seria um tópico novo ao qual a canção Der wunde Ritter de Nepomuceno faria menção. Além disso, como já apontamos acima, a peça de Nepomuceno também faz menção a tópicos mais antigos, como o toque de trombeta acima mencionado que se enquadraria nos tópicos militar e de caça, conforme foi extensamente estudado por Monelle (2006).

O que importa ressaltar aqui é que estas são evidências decisivas de que o estilo das canções de Nepomuceno nasce e se forja na assimilação de estilos e tópicos da música romântica universal, e não, como se pretendeu, apenas pela manipulação de registros folclóricos brasileiros. Tudo indica que, para Nepomuceno, o folclore, inclusive o brasileiro, representava um valor universal, um patrimônio cultural da humanidade que devesse ser compartilhado por todos, e não um estigma de identidade nacional que gerasse separação entre as culturas. Só assim podemos entender que ele tivesse se interessado, não só em absorver, mas em se expressar por

46 códigos musicais característicos do romantismo europeu, que ademais encontram profundas ressonâncias na cultura brasileira devido à colonização portuguesa.

É oportuno trazer agora à baila o problema de uma outra canção de Nepomuceno, daquele mesmo ano. Trata-se de Drömd Lycka, que mais do que qualquer outra canção de Nepomuceno parece imitar o estilo de Brahms. O Exemplo 4 traz os compassos iniciais que nos fazem lembrar de Brahms tanto pela figuração do acompanhamento como pelo caráter da linha melódica ondulante. 0 único manuscrito dessa canção existente no Brasil pertence à coleção particular de Sérgio Nepomuceno Alvim Correa. Ela não traz a identificação do autor dos versos que são transcritos em duas línguas: na linha superior em sueco e na inferior em alemão, na antiga caligrafia cursiva usada na época. Esse manuscrito, assim como outros daquela coleção, tem muitas anotações a lápis por cima da cópia a tinta. Comparando outros manuscritos da coleção com as edições publicadas, conclui-se que esses papéis são os rascunhos ou as versões preliminares dessas obras. As anotações a lápis são alterações projetadas pelo compositor para a versão 
definitiva. Especialmente instrutiva é uma versão fac-similar de 15 manuscritos de Nepomuceno publicada em 2000 pela Escola de Música Villa-Lobos. Aquelas cópias representam as versões passadas a limpo das canções, e as que coincidem com os rascunhos nos permitem compreender o sentido das alterações apontadas a lápis. Todavia, de modo geral, é impossível fazer perfeito sentido das alterações indicadas nos rascunhos apenas levando em conta os apontamentos a lápis. Há uma cópia de Drömd Lycka no acervo da Biblioteca Nacional que foi uma tentativa de Alvim Corrêa nesse sentido. Mas como se conclui da comparação de fontes, nem todas as alterações promovidas pelo compositor foram apontadas a lápis nos rascunhos e muitas são obscuras. Portanto a versão de Alvim Corrêa inevitavelmente apresentou problemas. Na edição da Edusp de 2004 optamos por usar apenas as informações à tinta do manuscrito, ignorando as anotações incompletas a lápis. Resultou que se publicou uma versão que reflete a intenção inicial do compositor, em que, pelo menos, comprova-se não haver incoerências.

Exemplo 4 Trecho inicial de Drömd Lycka de Nepomuceno

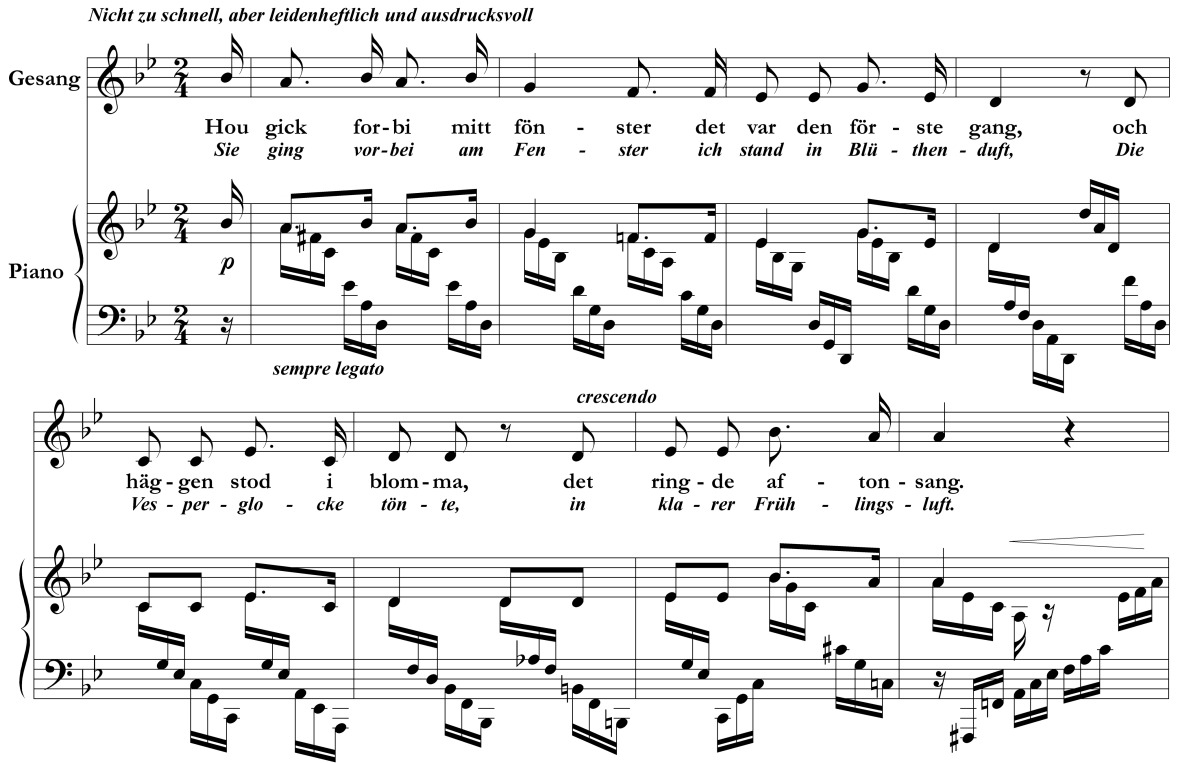

O músico Gustavo Tavares, residente na Noruega, informa por correio eletrônico ter localizado nos arquivos da editora norueguesa que publicou a Suite Antiga de Nepomuceno, uma cópia manuscrita passada a limpo de Drömd Lycka. 
Aguardamos com muito interesse a edição dessa versão revisada. Quanto ao poema, esse novo manuscrito parece também não resolver a questão da autoria. Entrementes constatamos um curiosa coincidência. O poema que precede Der wunde Ritter no Buch der Lieder de Heine, na edição de 1927, porta o título Die Fensterschau. A tradução para o alemão de Drömd Lycka, transcrita na segunda linha do manuscrito, intitula-se Geträumtes Glück, e tem muitas semelhanças com o poema de Heine. É possível que se trate de uma paráfrase daquele poema, escrita talvez pelo próprio Nepomuceno ou por sua mulher norueguesa, justificando-se assim a falta de anotação da autoria. Lembremos que Nepomuceno escreveu o libreto para sua ópera $A b u l$, o que faz supor que aquela não foi sua primeira incursão como autor de poemas que musicou. Transcrevemos abaixo a primeira estrofe dos dois poemas para que se possa avaliar a semelhança.

\begin{tabular}{|l|l|}
\hline Die Fensterschau (Heine) & Geträumtes Glück (anônimo) \\
\hline Der bleiche Heinrich ging vorbei, & Sie ging vorbei am Fenster, \\
Schön Hedwig lag am Fenster. & Ich stand in Blütenduft; \\
Sie sprach halblaut: Gott steh mir bei, & Die Vesperglokke tönte, \\
Der unten schaut bleich wie Gespenster! & In klarer Frühlingsluft. \\
\hline
\end{tabular}

Ainda que essa hipótese não possa ser comprovada, é certo que essas duas canções formam um par, assim como muitas outras de Nepomuceno também foram escritas aos pares, entre elas os opus 11, 14, 17, 18, 19, 20, 27 , 29, 30, 31, 32 e 34 que trazem sempre canções com números 1 e 2. Muitos desses emparelhamentos parecem seguir o padrão esboçado por aquelas duas canções do início da carreira: uma aproxima-se do estilo dos Folklieder de Brahms (como é o caso de Der wunde Ritter) e a outra do estilo dos Kunstlieder (como é o caso de Drömd Lycka).

O interesse de Nepomuceno por Heine não esmoreceu nas primeiras canções. O opus 19 também utiliza dois poemas em alemão. O primeiro deles, de Heine (Mir träumte), enquadra-se na categoria dos Folklied, pois inspirou Nepomuceno a usar o ritmo da valsa, que tal como em Mahler, ganha conotações 
de música vulgar. O segundo (Liebeslied) é de uma desconhecida Condessa Amadei (Gräfin Anna Antonia Amadei, nascida Rosty von Barkocz [1828-1927]), e embora menos complexo, lembra a textura de Drömd Lycka e pretenderia ser um Kunstlied. Embora inicialmente compostas para o texto em alemão, ambas as peças receberam tradução para o português de Nepomuceno (a cópia manuscrita de Liebeslied da Escola de Música Villa-Lobos só tem o texto em alemão, o que prova que a tradução foi feita posteriormente). Essa é uma indicação significativa do sentido que teve a questão do canto em português para Nepomuceno. Voltaremos ao assunto na segunda parte deste estudo.

Lembremos ainda que um elemento distintivo do estilo de Heine é seu humor irônico. Youens (2007, p. xix) comenta que muitos autores românticos foram insensíveis à essa característica fundamental do estilo Heine ao musicar seus poemas. Não é o caso de Nepomuceno. Mir träumte (Sonhei) é exemplar na resposta musical ao humor de Heine: inicialmente o poema descreve, em tom ironicamente kitsch, o enlevo do poeta em seu idílio amoroso. Todavia, no desenlace, os beijinhos da amada se convertem inesperadamente numa dentada... Como mencionamos acima, Nepomuceno utiliza aqui um de seus tópicos estilísticos favoritos, a valsa com acentos cômicos. Lembremos, por exemplo, de seu ciclo de Valsas Humorísicas para piano e orquestra que desenvolve essa tópica sob diversas perspectivas de associação e intertextualidade.

Mir träumte utiliza constantes mudanças de figurações de acompanhamento, recuperando ainda uma vez a lição aprendida de Brahms. Além do mais, a mudança de texturas resulta numa importante função de alternância de tópicos: em rápida sucessão aparecem a valsa, um recitativo acompanhado (com dobramento da voz), outro recitativo acompanhado (mas desta vez ansioso e sincopado), culminando num recitativo seco no momento em que o texto se refere à dentada (num efeito inesperado, deslocando a atenção para o texto, e por isso eficiente no propósito semântico), continuando com um novo recitativo acompanhado que remete ao melodrama e ao estilo operístico italiano, que a seguir se converte em outro recitativo seco para acompanhar o verso final, que glosa, num comentário final, a dentada da amada. Uma Coda, simétrica à introdução, faz retornar o fragmento de valsa, num comentário final de 
piano solo, ao estilo de Schumann, que esclarece definitivamente a significação humorística da canção. É importante notar que, embora a tradução para o português preserve a essência da relação texto-música, é evidente, pela adequação da prosódia, que a peça foi composta sobre o texto original em alemão. Ainda assim é uma peça que considero uma das melhores do cancioneiro de Nepomuceno, pois reflete primorosamente as vivências culturais da sociedade burguesa carioca de sua época. A sentimentalidade exagerada comentada com distanciamento crítico e humor irônico faz desta canção um perfeito correlato musical dos melhores contos de Machado de Assis. E, tal como para Machado a fonte inspiradora do estilo havia sido a literatura inglesa, para Nepomuceno foi o Lied alemão.

Exemplo 5 Final de Mir träumte de Nepomuceno, sobre poema de Heine

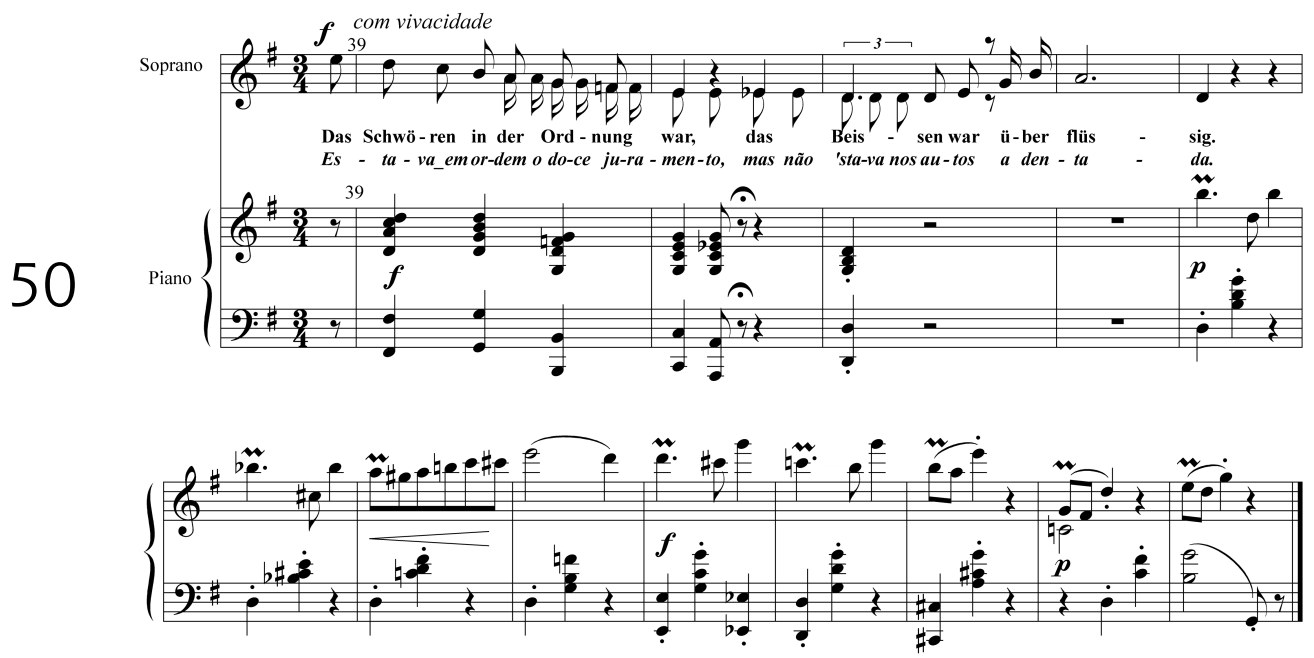

Nepomuceno não retornaria mais a versos de Heine depois desta canção. Entretanto o modelo bem sucedido do lirismo irônico ecoaria em outras canções. Uma delas é Trovas Op. 29 n. 2, sobre texto de Magalhães Azeredo. Este é um poeta pouco reverenciado hoje em dia, aliás como muitos outros parnasianos, mas a seu tempo teve prestígio suficiente para ser o mais jovem ocupante de uma cadeira na Academia Brasileira de Letras. Certamente contribuiu para isso o apreço que Machado de Assis Ihe dedicava. A relação muito próxima entre os dois escritores é testemunhada por 
uma extensa troca de correspondências, propiciada por Magalhães Azeredo ter vivido a maior parte de sua vida no exterior, servindo como diplomata.

O poema em questão é também vazado de ironia, nos lembrando o humor de Heine e Machado de Assis. A função da valsa em Mir Träumte é substituída aqui pelo ritmo de fandango. Novamente encontramos as mudanças de texturas do acompanhamento que enfatizam as mudanças de sentido do poema. No início o assunto parece ser uma serenata convencional. Entretanto, na estrofe central, o poeta revela "que não canta para a amada, mas para a lua que sorri”. E no verso final dá um último golpe de rejeição sarcástica, mandando a namorada embora.

Exemplo 6 Três trechos das Trovas Op.29 n. 2 de Nepomuceno
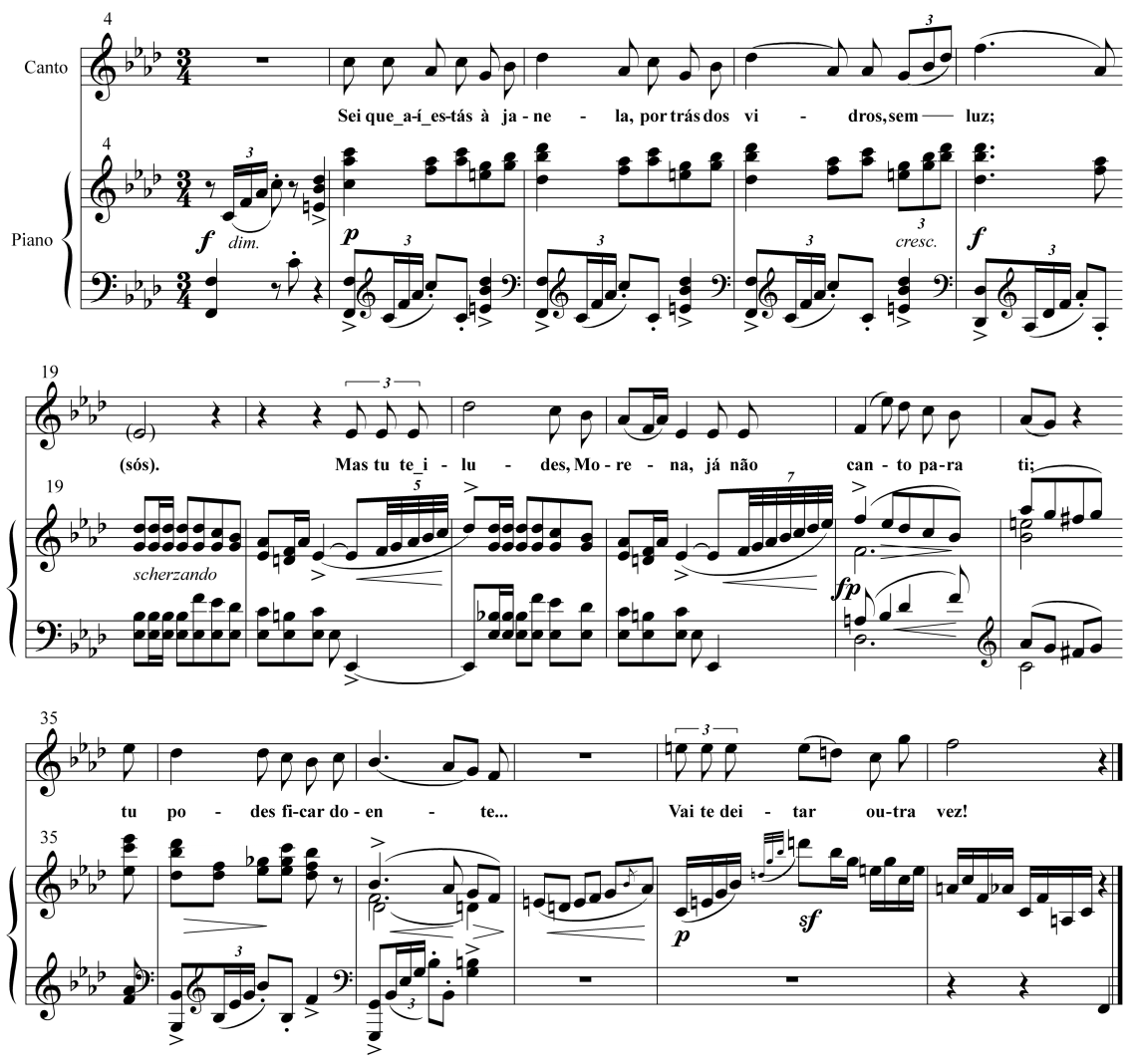

Esta canção, uma das mais conhecidas de Nepomuceno, é valorizada porque expressaria tendências nacionalistas, se dermos crédito à historiografia 
modernista. Ora, o intrigante é constatar que nela não há de fato nenhuma referência folclórica. O fandango é uma dança de origem ibérica, tão antiga que foi utilizada por Luigi Boccherini e Antonio Soler no século XVIII. É muito mais provável que Nepomuceno tenha se interessado pelo fandango devido ao contato com espanhóis e portugueses que imigraram para o Rio de Janeiro do que por alguma pesquisa folclórica em outra região do Brasil em que o fandango tenha sido assimilado como manifestação folclórica.

Portanto, para Nepomuceno, o fandango é um tópico estilístico, tal como a valsa, o minueto ou a marcha. E aliás, note-se, Nepomuceno tem perfeita compreensão da carga semântica do tópico que está utilizando, pois, na tradição ibérica, o fandango é uma dança de sedução entre pares de homens e mulheres que executam jogos de conquista e rejeição permeados de humor e ironia. Portanto Nepomuceno tinha plena consciência da adequação deste tópico ao sentido do poema, e provavelmente esperava que seu público fosse também capaz de reconhecer essas significações.

Ainda outra vez, comparando os opus 29 n. 1 e 2, constatamos a mesma oposição entre Kunstlied, no n. 1 e Volkslied, no n. 2, conforme o modelo

52 assimilado de Brahms. Todavia note-se que Brahms não o utilizava desta maneira, isto é, como contraste entre canções emparelhadas.

Enfatizemos finalmente que o conceito romântico de Volkslied a que Nepomuceno adere é essencialmente diferente do ideal perseguido pela geração modernista subsequente que buscará no folclore uma garantia de identidade nacional. Para Nepomuceno o interesse pelo folclore era uma questão de afinidade eletiva, e muito menos uma profissão de fé.

\section{Referências}

AGAWU, Kofi. Music as Discourse. Oxford: Oxford University Press, 2009.

COELHO de SOUZA, Rodolfo. Aspectos de modernidade na música de Nepomuceno relacionados ao projeto de tradução do "Harmonielehre" de Schoenberg. Revista Em Pauta (UFRGS), v.17, série 29, p. 63-8, 2006. . Influência e Intertextualidade na Suite Antiga de Alberto Nepomuceno. Música em Perspectiva, v.2, p. 35-66, 2008. 
HANCOCK, Virginia. "Volkslied/Kunstlied". In: HALLMARK, Rufus (Ed.) German Lieder in the Nineteenth Century. New York: Schirmer, 1996.

KIEFFER, Anna Maria. No tempo da modinha. Entrevista para a Revista de História da Biblioteca Nacional. Disponível em: <http://www.revistadehistoria. com.br/v2/home/?go = detalhe\&id=1302, 2007>.

MARIZ, Vasco. A Canção Brasileira de Câmara. Rio de Janeiro: Francisco Alves, 2002.

MONELlE, Raymond. The Musical Topic: Hunt, Military and Pastoral. Bloomington: Indiana University Press, 2006.

NEPOMUCENO, Alberto. Canções para voz e piano. PIGNATARI, Dante (Ed.). São Paulo: Edusp, 2004.

RATNER, Leonard. Classic Music: Expresions, Form and Style. New York: Schirmer, 1980.

YOUENS, Susan. Heinrich Heine and the Lied. Cambridge: Cambridge University Press, 2007.

E-mail: rcoelho@usp.br

Artigo recebido e aprovado em 2 de novembro de 2010 